This item was submitted to Loughborough's Research Repository by the author.

Items in Figshare are protected by copyright, with all rights reserved, unless otherwise indicated.

\title{
Grain size control in the weld pool and heat affected zone using holograms
}

PLEASE CITE THE PUBLISHED VERSION

http://dx.doi.org/10.4028/www.scientific.net/MSF.715-716.340

\section{PUBLISHER}

(C) Trans Tech Publications

\section{VERSION}

AM (Accepted Manuscript)

\section{PUBLISHER STATEMENT}

This work is made available according to the conditions of the Creative Commons Attribution-NonCommercialNoDerivatives 4.0 International (CC BY-NC-ND 4.0) licence. Full details of this licence are available at: https://creativecommons.org/licenses/by-nc-nd/4.0/

\section{LICENCE}

CC BY-NC-ND 4.0

\section{REPOSITORY RECORD}

Higginson, Rebecca L., M. Blackmur, Matt Gibson, and John R. Tyrer. 2014. "Grain Size Control in the Weld Pool and Heat Affected Zone Using Holograms". figshare. https://hdl.handle.net/2134/15858. 


\title{
Grain Size Control in the Weld Pool and Heat Affected Zone Using Holograms
}

\author{
$\underline{\text { R.L.Higginson }}^{1 \mathrm{a}}$, M.Blackmur ${ }^{\text {1b }}$, M.Gibson $^{2 \mathrm{c}}$, J.Tyrer $^{2 \mathrm{~d}}$ \\ ${ }^{1}$ Department of Materials, Loughborough University, Loughborough, LE11 3TU, UK \\ ${ }^{2}$ Wolfson School of Mechanical and Manufacturing Engineering, Loughborough University, \\ Loughborough, LE11 3TU, UK. \\ ${ }^{a}$ R.L.Higginson@lboro.ac.uk, ${ }^{b}$ MPMB3@lboro.ac.uk, ${ }^{c}$ M.Gibson@lboro.ac.uk, \\ dJ.R.Tyrer@lboro.co.uk
} Keywords: Laser welding, Holograms, Grain Size Control, Heat Affected Zone, Electron
Backscatter Diffraction

\begin{abstract}
This paper considers the use of Holographic Optical Elements (HOEs) to shape the weld beam and hence control the grain size of the weld bead and the grain growth and phase transformations in the HAZ. Welds have been produced on carbon steel with the introduction of a nickel based filler powder, using different energy densities produced by the HOEs. Cross sections of the welds have been analysed in terms of the weld profile, weld pool shape and grain size in the deposit and the HAZ. Electron BackScatter Diffraction (EBSD) coupled with Energy Dispersive $\mathrm{X}$-ray Spectroscopy (EDS) has been used to study the microstructures developed. The results have shown that by utilising HOE's the grain size within the weld pool can be controlled such that a more equiaxed grain structure is developed when compared with the coarse columnar grains seen with a Gaussian beam.
\end{abstract}

\section{Introduction}

Conduction laser welding involves initiating a melt pool by exposure of the metal to a high power laser induced light and controlled thermal conduction. The energy supplied to the metal is usually sufficient to melt a localised area with further heating to the Heat Affected Zone (HAZ). The microstructure of a weld bead is usually made up of coarse columnar grains growing out from the bead/substrate interface. The large grain size and high aspect ratio developed may be detrimental to the properties of the weld bead in terms of both mechanical and physical properties [1]. In addition to this, the welding process has a thermal effect on the surrounding substrate metal within the HAZ which can cause phase changes close to the bead substrate interface and possibly recrystallisation and/or extensive grain growth depending on the distance from the weld interface and the welding conditions.

In traditional laser welding the laser beam is directed into the work piece using standard optical lenses and a Gaussian (circular) energy distribution. The Gaussian beam has a peak in energy at the centre which decreases rapidly towards the edges leading to an uneven or excessive localized heating into the weld bead and HAZ. This excess heating can lead to poor microstructures and increased residual stresses which are undesirable when using laser welding for repair of components [2,3]. A number of studies have shown changes in the bead microstructure through the use of shaped laser beams [4,5]. Work at Loughborough University has led to the development of Holographic Optical Elements (HOEs) which use bespoke holograms that can be used to shape the beam to any desired profile [3,4]. Initial results using autogenous welds on stainless steel have shown that by using these optics a squarer more homogeneous weld profile can be produced with the ability to shape the profile of the HAZ as well as the microstructure [4]. The present paper considers the use of these optics for the deposition of new metal onto a substrate which could be used in the cladding of new material or component repair. 


\section{Experimental Procedure}

The substrate metal used was a $1.5 \mathrm{~mm}$ thick steel sheet containing $\sim 0.12 \% \mathrm{C}$, the chemical ranges are shown in Table 1. The grain size of the sheet was determined using quantitative optical microscopy to be $29 \times 13 \mu m$ elongated in the rolling direction. The sheet was cut into sections and mechanically cleaned, washed in alcohol and dried to remove any surface contamination. The sheets were laser cut into small coupons to ensure that there was no heat conduction between the neighboring track regions during the welding process. The work piece was then clamped between two plates of $5 \mathrm{~mm}$ mild steel with a $15 \mathrm{~mm}$ thick Duratec insulation board beneath the substrate and the assembly was fixed to the CNC table. Nickel based Inconel 625 power with the composition shown in Table 1 was laid down in tracks, $0.25 \mathrm{~mm}$ thick, across the coupons prior to the laser being passed across the surface.

Table 1: Chemical compositions of the steel substrate and the Inconel 625 filler powder

\begin{tabular}{|c|c|c|c|c|c|c|c|c|c|c|c|c|c|c|}
\hline & $\begin{array}{c}\mathbf{F e} \\
\mathrm{wt} \%\end{array}$ & $\begin{array}{c}\mathbf{C} \\
\mathrm{wt} \%\end{array}$ & $\begin{array}{c}\text { Mn } \\
\mathrm{Wt} \%\end{array}$ & $\begin{array}{c}\mathbf{P} \\
\text { wt\% }\end{array}$ & $\begin{array}{c}\mathbf{S} \\
\mathrm{wt} \%\end{array}$ & $\begin{array}{c}\mathbf{N i} \\
\mathrm{wt} \%\end{array}$ & $\begin{array}{c}\mathbf{C r} \\
\mathrm{wt} \%\end{array}$ & $\begin{array}{c}\text { Co } \\
\text { wt\% }\end{array}$ & $\begin{array}{c}\text { Mo } \\
\text { wt\% }\end{array}$ & $\begin{array}{c}\mathbf{T i} \\
\mathrm{wt} \%\end{array}$ & $\begin{array}{c}\text { Al } \\
\mathrm{wt} \%\end{array}$ & $\begin{array}{c}\mathbf{S i} \\
\mathrm{wt} \%\end{array}$ & $\begin{array}{c}\text { Nb } \\
\text { wt\% }\end{array}$ & $\begin{array}{c}\mathbf{K} \\
\text { wt\% }\end{array}$ \\
\hline Substrate & Bal & $\begin{array}{l}0.12 \\
\max \end{array}$ & $\begin{array}{l}0.60 \mathrm{~m} \\
\mathrm{ax}\end{array}$ & $\begin{array}{l}0.05 \\
\max \end{array}$ & $\begin{array}{l}0.05 \\
\max \end{array}$ & - & - & - & - & - & - & - & - & - \\
\hline Powder & $\begin{array}{c}5 \\
\max \end{array}$ & $\begin{array}{l}0.10 \\
\max \end{array}$ & $\begin{array}{l}0.50 \\
\max \end{array}$ & - & $\begin{array}{c}0.015 \\
\max \end{array}$ & 58 & $20-23$ & $\begin{array}{c}1.0 \\
\max \end{array}$ & $\begin{array}{c}8 \\
-10\end{array}$ & $\begin{array}{l}0.40 \\
\max \end{array}$ & $\begin{array}{l}0.40 \\
\max \end{array}$ & $\begin{array}{l}0.50 \\
\max \end{array}$ & $\begin{array}{c}3.15 \\
- \\
4.15\end{array}$ & $\begin{array}{c}0.015 \\
\max \end{array}$ \\
\hline
\end{tabular}

A $1 \mathrm{~kW} \mathrm{CO}$ Coherent Everlase S48 laser was used which was fitted either with a coaxial focusing head to produce a Gaussian distribution, Fig.1 (a) or a cabinet containing a Holographic Optical Element (HOE). Two HOE profiles were use; a "Half Pipe" distribution and a "Half Pipe Wedge" distribution which was used both with the wedge on the leading and trailing edge of the weld. These distributions have been developed following a number of investigations (6-10). A graphical representation of these two profiles is shown in Fig.1 (b\&c) respectively. The work piece was set at different depths below the focal point of the cutting head to give a beam diameter matching the width of the customised beam, beam dimensions were checked using beam prints in Perspex. The welds were made using a low flow rate $(10 \mathrm{l} / \mathrm{min})$ air assist gas to keep spatter and fume from contaminating the laser optics. Welds tracks $\sim 60 \mathrm{~mm}$ in length were completed on each coupon and the sheet removed, sandblasted to remove oxide layer and the individual coupons separated.

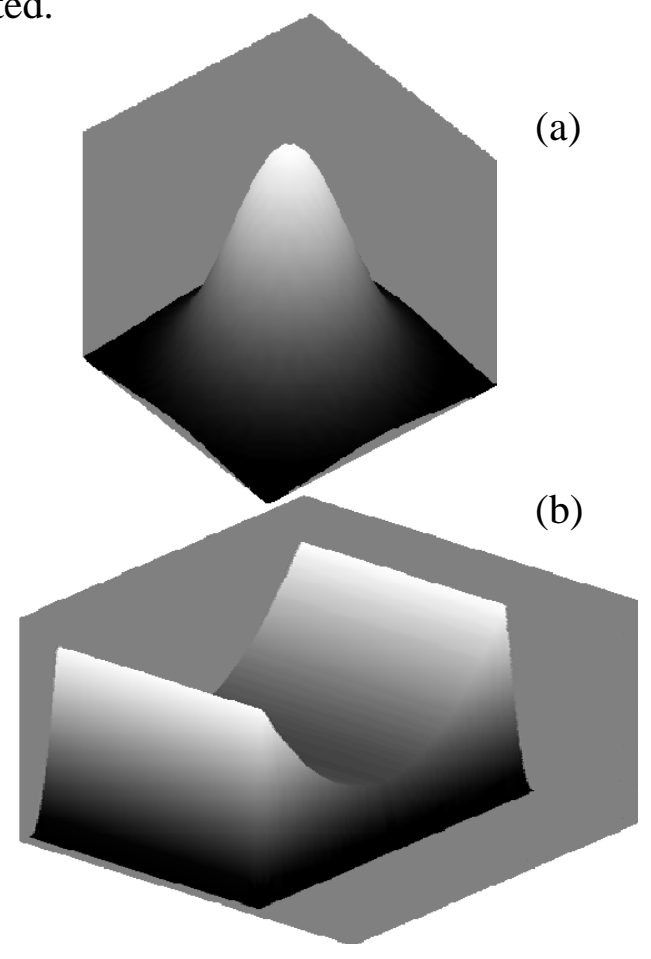

Figure 1: Beam profiles (a) Gaussian (b) Half Pipe distribution and (c) Half Pipe Wedge distribution which was used both with the wedge on the leading (left to right) and trailing edge (right to left).

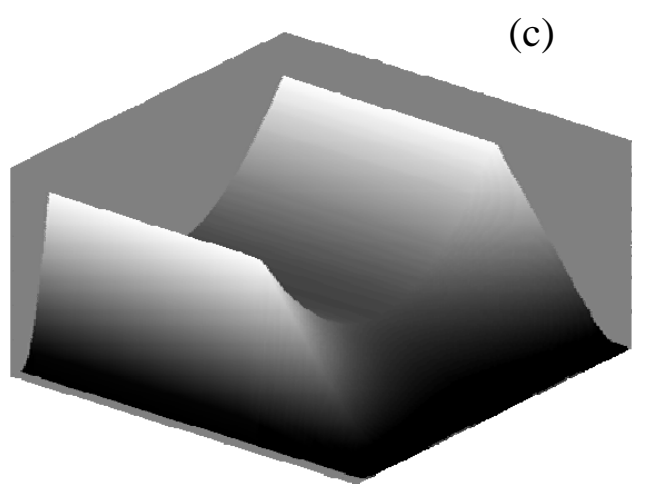


Following deposition the welds were sectioned in the transverse direction, mounted in conductive Bakelite, ground to 1200 grit and polishing on 6 and $1 \mu \mathrm{m}$ diamond with a final polish using colloidal silica just prior to examination using electron microscopy. The samples were examined in a LEO 1530VP Field Emission Gun Scanning Electron Microscope (FEG-SEM) equipped with a TSL-EBSD system with 'Delphi' phase identification and OIM analysis packages. The software allows simultaneous EDS data to be collected during the EBSD scans. Following EBSD examination the samples were etched in $2 \%$ Nital to reveal the microstructure of the substrate and optical micrographs taken.

\section{Results and Discussion}

Fig.2 shows optical micrographs of the deposits of nickel on steel produced by the Gaussian beam Fig.2(a) and the HOEs, Fig 1(b-d).
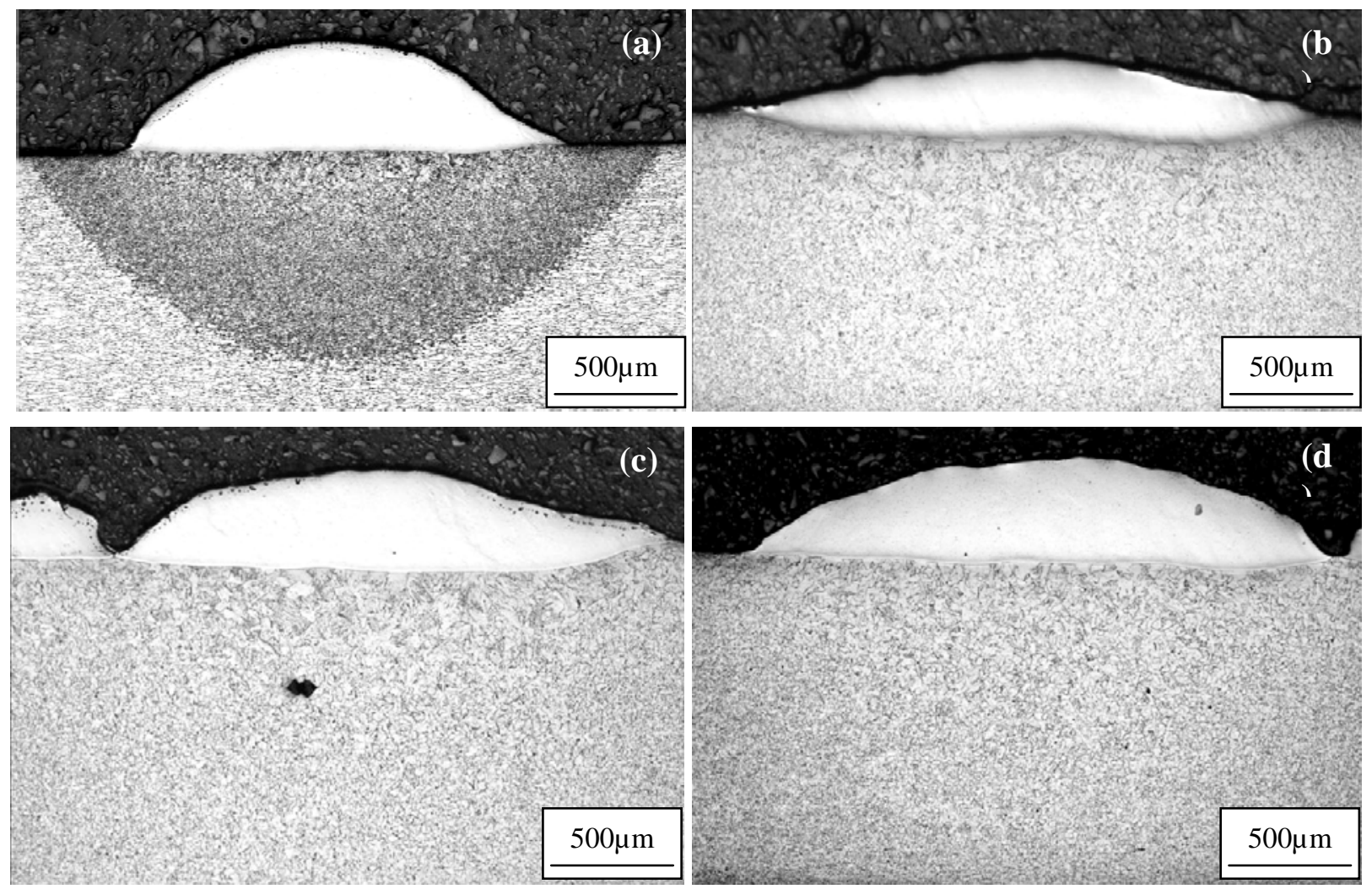

Figure 2: Optical micrographs of nickel deposited onto a steel substrate using (a) a Gaussian beam (b) a Half Pipe HOE, (c) a Half Pipe Wedge HOE with the peak edge trailing (d) a Half Pipe Wedge HOE with the peak edge leading. The samples were etched in $2 \%$ Nital.

In the micrograph of the Gaussian deposit, Fig.2(a), the HAZ below the weld is clearly visible in the substrate. Below the weld bead the HAZ consists of acicular ferrite beneath which there is a fine grained recrystallised region that extends to more than half of the substrate thickness. The structure of the weld deposit produced by the Half Pipe HOE is shown in Fig.2(b). The deposit is wider than that seen with the Gaussian with a flatter profile and is therefore thinner. In this sample the extent of the HAZ is wider than with the Gaussian and is less defined. There is evidence of acicular ferrite below the bead in the substrate. With the Half Pipe Wedge HOE used with the peak edge trailing (Fig.2 (c)) the weld bead is not homogeneous and there is a small amount of nickel that has been sputtered to one side as seen on the left of Fig.2(c). The shape of the bead is also inhomogeneous with a dip in the deposit to the right. The HAZ shows a thicker layer of acicular ferrite beneath the deposit extending to $\sim 300 \mu \mathrm{m}$ into the substrate. The Half Pipe Wedge HOE run with the peak edge leading is shown in Fig .2(d). Due to the design of the optic in this direction there is a slower cooling rate following the peak power. The shape of the deposit it more homogenous and the bead it is squarer compared to that seen in Fig.2(c) which was made with the 
same optic. The HAZ is less evident under deposit with only a very small amount of acicular ferrite just below the bead with a small grain size seen in the substrate.
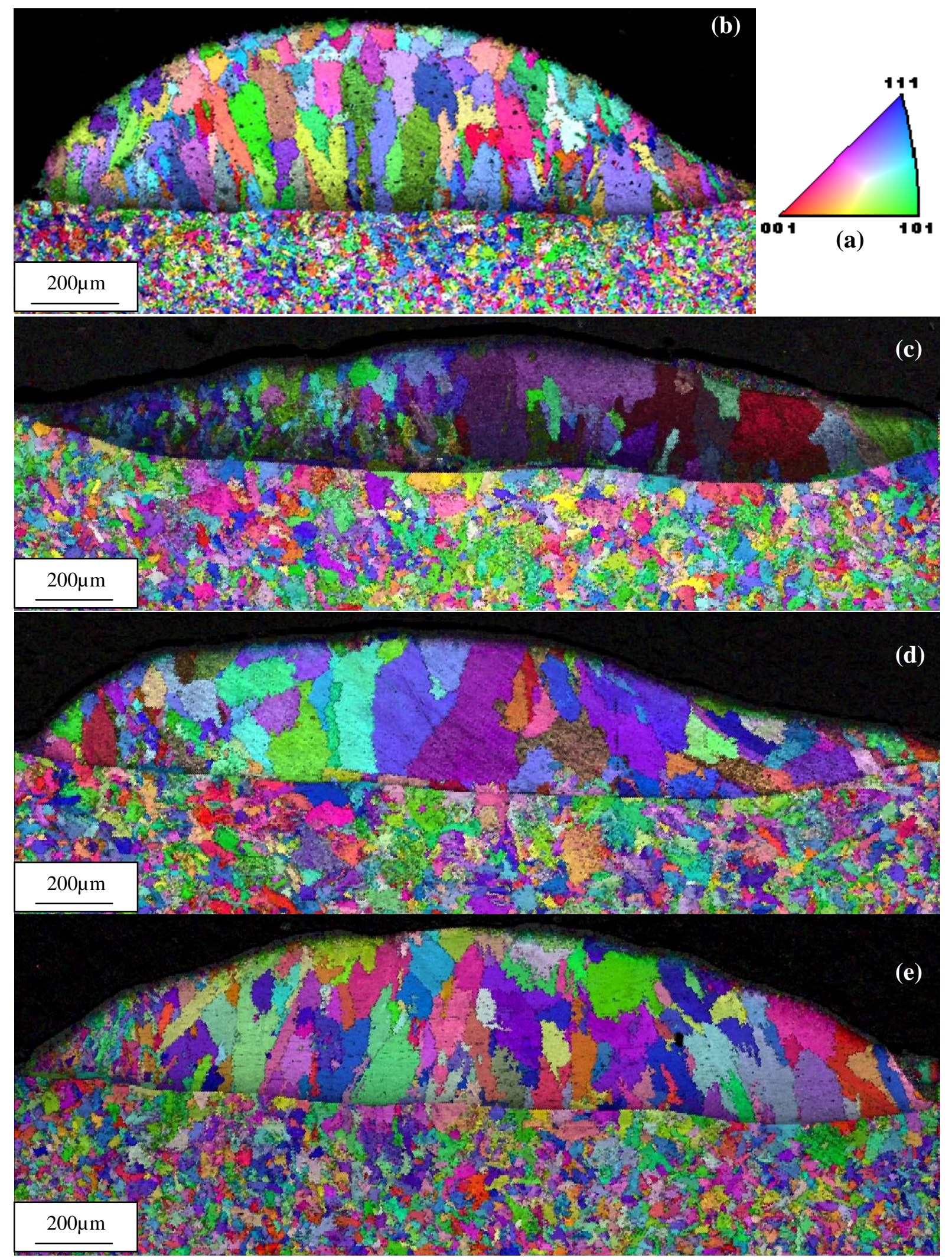

Figure 3: Electron Back-Scatter Diffraction (EBSD) maps of Image Quality (IQ) and Inverse Pole Figure (IPF) plot of the grain orientation. The key for the IPF colours is given in (a) with the maps for (b) the Gaussian beam, (c) the Half Pipe HOE, (d) a Half Pipe Wedge HOE with the peak edge training (e) a Half Pipe Wedge HOE with the peak edge leading.

Fig. 3 shows EBSD maps of the nickel deposits seen in Fig.2. The results are plotted as Image Quality (IQ) data which gives a measure of the sharpness of the Kikuchi patterns, overlaid onto the 
Inverse Pole Figure (IPF) plot which plots the orientation of a given point with reference to the standard stereographic triangle shown in Fig 3 (a). The EBSD map for the Gaussian deposit is shown in Fig.3 (b). ED(X)S analysis of similar deposits has demonstrated that there was no mixing between the deposit and the substrate material [3]. The grain size within the deposit is large and columnar with an aspect ratio of $\sim 2.5$, with smaller equiaxed grains near the surface of the bead. The grain size of the deposit produced by the Half Pipe, Fig.3(c), is clearly larger than that of the Gaussian and is inhomogeneous across the centre line of the bead. The grains are larger on the right of the bead and considerably smaller on the left. This grain size distribution is unexpected as the HOE is symmetrical about the center line. The area below the weld bead shows considerable grain growth with large grains seen both next to the interface and into the substrate.

With the introduction of the slow heating rate in the Half Pipe Wedge with the trailing peak edge, Fig.3(d), the grain size is more homogeneous and equiaxed, but larger than that seen in the Gaussian deposit, Fig.3(b). The grain size is large with grains extending from the surface of the bead to the interface. There is also evidence of considerable grain growth in the HAZ particularly beneath the centre of the weld where there was evidence of acicular ferrite seen in the optical images Fig.2. With the same optic run with the peak edge leading, Fig.3 (e) the shape of the deposit is more homogeneous and has a squarer profile. The grain size is smaller and more equiaxed than the deposit made with the optic run in the opposite direction, Fig 3.(d). The grain size in the HAZ also appears smaller then the weld produced by the other HOE's which is consistent with the optical observations in Fig.2.
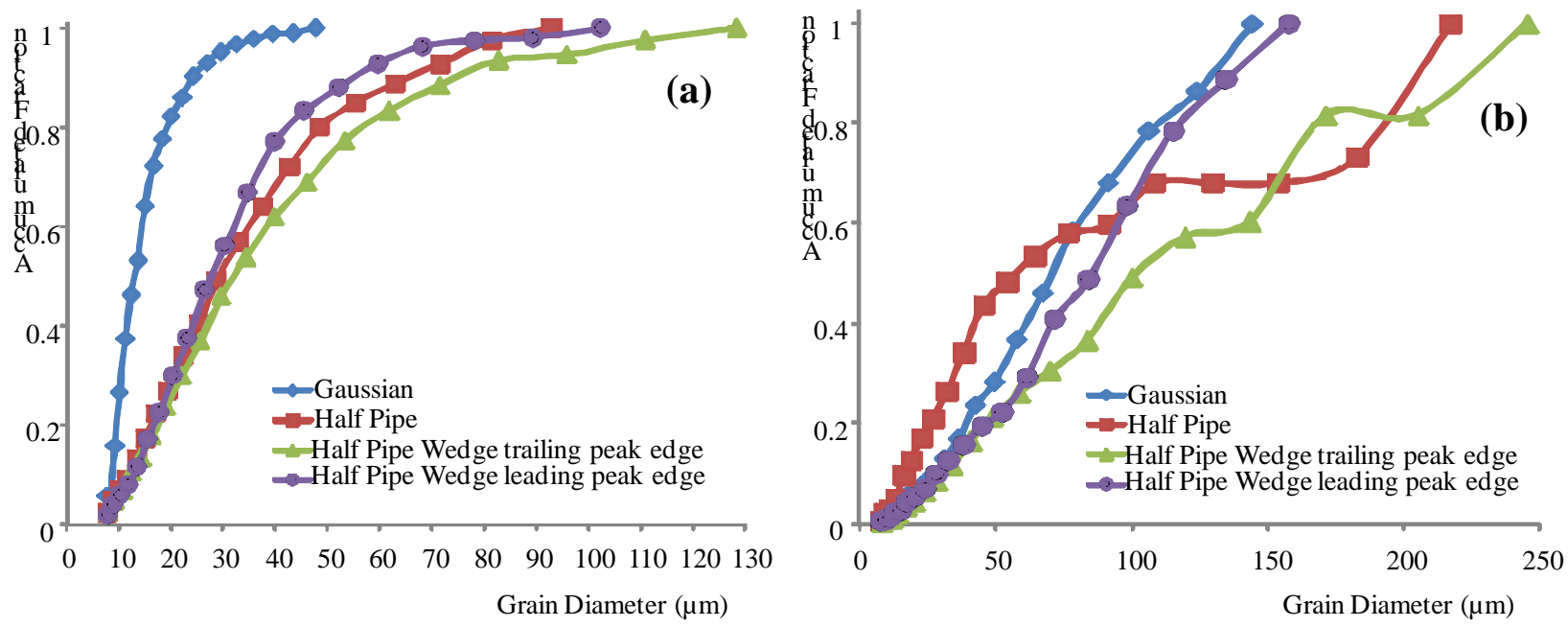

Figure 4: Plots of grain diameter in (a) the sub weld HAZ $(200 \mu \mathrm{m})$ and (b) the weld bead determined by EBSD.

The grain sizes in both then HAZ and the weld bead were determined from the EBSD maps and are plotted in Fig.4. Although the grains in the Gaussian deposit have the highest aspect ratio it also has the smallest average grain size, Fig 4(b). This result is due to the layer of fine grains at the surface of the deposit, Fig.3 (b). The grain size in the Half Pipe and the Half Pipe Wedge with the peak edge trailing are bimodal with the latter showing the larger grain size. The grain size of the deposit with the Half Pipe wedge with the peak edge leading is similar to that of the Gaussian deposit but the grains are more equiaxed.

The grain size in the HAZs are shown in Fig.4.(a). The grain size in the HAZ in the Gaussian deposit is the smallest however, this is mainly due to the large area of recrystallised grains around the edge of the HAZ, Fig.2.(a). The largest grain size is seen in the Half Pipe Wedge with the peak edge training i.e. with the slow heating rate with the smallest grains in HOE deposits see in the Half pipe wedge with the leading peak edge or with the slower cooling rate following the peak energy.

These results indicate that by shaping the HOE profile to introduce a slower cooling in the weld following the peak energy, a finer more equiaxed grain size can be induced in the weld bead as well as a squarer bead profile produced. The slower cooling rate also has a significant effect on the 
grain growth in the HAZ with a smaller grain size and a reduced amount of acicular ferrite seen with the slower cooling rate.

\section{Conclusions}

Tailored energy distributions have been produced by Holographic Optic Elements (HOEs). With these optics it is possible to control the energy distribution of the beam as well as the heating and cooling rates. By introducing a slower cooling rate it is possible to produce a deposit with a more equiaxed grain shape and squarer bead profile. The grain size control, however, requires the optimisation of the peak energy to beam width ratio and the rate of post peak cooling, such that the energy applied to the material optimises the cooling rate. This slow cooling rate has a significant effect on the grain growth within the HAZ. With a Gaussian beam there was evidence of the development of acicular ferrite and an extensive recrystallised region. With the use of the HOE this effect was reduced with the slower cooling rate leading to less grain growth in the HAZ. This gives the added potential of controlling the microstructure in the HAZ which is important both when using lasers for surface treatment and for multi layered deposits.

\section{References}

[1] A.L. Greer: Materials Science and Engineering A, Vol.133, (1991) p.16.

[2] M. Vedani, B. Previtali, G.M. Vimercati, A. Sanvito, G. Somaschini, Surface and Coatings Tech. Vol. 201(8), (2007), p.4518.

[3] J. Kell, J.R. Tyrer, R.L. Higginson, and R.C. Thomson, Journal of Microscopy, Vol. 2172, (2005), p.167.

[4] J.Khare, R.Kaul, P.Ganesh, H.Kumar, R.Jagdheesh, A.K.Nath, J.Laser Appl. Vol.19(1), (2007), p.1.

[5] A.J.Pinkerton, L.Li, J.Laser Appl. Vol.17 (2005), p.47.

[6] R.L.Higginson, M.R.Gibson, J.Kell, and J.R.Tyrer, Materials Science Forum, Vol. 638-642, (2010), p.3673.

[7] M.R.Gibson, J.R.Tyrer, R.L.Higginson, Proc. ICALEO 2008 Congress Proceedings, Temecula, CA (2008), p.57.

[8] M.R.Gibson, J.R.Tyrer, R.L.Higginson, Proc. ICALEO 2008 Congress Proceedings, Temecula, CA (2008), p.7.

[9] M.R.Gibson, J.R.Tyrer, R.L.Higginson, M.Blackmur, ICALEO 2009 Congress Proceedings; LMP Conference (2009), p.653.

[10] M.R.Gibson, J.R.Tyrer, R.L.Higginson, ICALEO 2009 Congress Proceedings; LMP Conference (2009), p.545. 